IDEAS IN ECRLGGY AND EVRLutIIN 4: 43-47, 2011

doi:10.4033/iee.2011.4.9.e

(C) 2011 The Author. (C) Ideas in Ecology and Evolution 2011

Received 19 December 2011; Accepted 19 December 2011

\title{
Editarial
}

\section{Money for nothing and your referees for free}

\section{Christopher J. Lortie}

Christopher J. Lortie (lortie@yorku.ca), Department of Biology, York University, Toronto, Ontario, Canada, M3J 1P3

\section{Preamble}

Academics pursue knowledge and truth. It is a real privilege to be paid, at least part of the time, to think, write, conduct research, and solve problems (and teach - which may or not be included in the perception of privilege, depending on the person). An easy identifier of our labor is publications. We assume that what sets these publications apart from other written endeavors is that they are published in journals and are peer-reviewed. Other formats, such as various periodicals, are also very similar to journals, but it is my understanding that these articles - for the most partare formally reviewed only by editors and not by peers. The contribution of peers is therefore the critical element that differentiates scientific publications from any other source (van Kolfschooten 2002, Ware 2008). It provides legitimacy, and establishes and protects a reputation for our work which the public can largely trust (Giles 2006). A survey of several thousand referees conducted by the publishing research consortium using Thomson Scientific referee emails confirms my own view that academics continue to support peer review (93\%) and that review is perceived as improving quality (90\%) (Ware 2008). Nonetheless, I see only a minor role for publishers in this process. I may be naïve in the vagaries of disseminating results, but it strikes me as strange that academics write the grants and secure the funding to do the work, then do the work (or at least supervise graduate students doing it), and write up the findings. These are then passed to our senior, established colleagues who serve as editors, who then solicit the reviews of peers who both improve and quality check the work (including the writing and style). Publishers then take over to typeset and disseminate the product. The analogy of this process would be running a relay race with an unbalanced team. Scientists run every step of the long race, but then pass the baton to publishers just as we are about to approach the finish line - thereby relinquishing our copyright, our ability to control how the work is disseminated, and our portion of the profits or how they are shared.

Advertising, typesetting, and distributing the content is not trivial. In the age of the Internet, however, other models of publication exist with considerably less expense and time to produce. Presumably, then, some of the very significant costs that our institutional libraries in turn have to pay must be associated with profit because most journals are concurrently available online anyway. Taxpayers fund our salaries, and grants fund our research, our page and reproduction charges, the additional charges for the privilege of open access, and often partially fund the libraries. The libraries then pay publishers so we can access our own work even though we have run virtually the entire distance in the relay race, having written and edited our work ourselves. Importantly, our race team sponsors-the public and other funding agencies - also get limited recognition for the money they invest in our endeavor. In essence, public funds pay twice for the work: to do it and then for access to it. The latter cost is being paid not to public servants or universities, but to companies. Two solutions come to mind immediately. The first is to not pass the baton, or, pass the baton but ensure that there is 
a place on the finish podium for all the runners on the team to share the tangible rewards. Let's explore the second option here.

Society journals negotiate specific arrangements on the share of the profit that is returned to themselves, and subsequently returned to its membership. In no way do I wish to see this reciprocity change. The societies are participants in a flawed system. However, without transparency, it is difficult to assess or know in many instances who is accruing the financial benefit of a specific journal. Much as one wants to know what proportion of a donation made to a non-profit institution makes it to the intended recipient, it is reasonable to demand that the science journals we submit to and review for gratis communicate to us how the finance side is managed. A more direct demand would be for compensation in terms of either payment, either for publication in journals, or for service in our efforts to ensure that the quality of our work collectively is sustained. In the former instance, the primary author of a paper could be granted a nominal per diem for publication in a journal which she/he could choose to redirect to the society, a graduate student, or a research grant. However, it is dubious and perhaps unethical that we should get paid twice for completing our workonce to do the work and once to publish it - and I am not proposing that. Publications have value, and we are not effectively leveraging them in any regard. Limited recognition for one's institution, country, and funding body may be compensation enough, but it is still reasonable to question how the net value or worth of our papers is managed. We could do much more with these entities.

In the latter instance above, remedying the 'money for nothing' (i.e. money paid to provide profits for publishers) and 'peer review for free' situation is likely a more compelling avenue with respect to inventing rewards; this has been explored in various forms in ecology and evolution. The primary reason that changes to the system have been considered is the increased difficulty in securing referees by editors in ecology and evolution (Hochberg, et al. 2009, Hochberg 2010) although we have seen little evidence of solutions to this issue proposed by publishers. In some instances, punishments have been proposed as a means to incentivize peer review (Davidoff 2006, Hauser and Fehr 2007), but I personally prefer rewards. Rewards have been proposed such as publication credits (Fox and Petchy 2010) or recognition by the community via mechanisms including positive scores such as the peerage of science (www.peerageofscience.org). However, these seem counterintuitive because the publishers are the individuals that cross the finish line and collect the reward. A relay runner would not demand recognition for running her part of the race from a bystander but from the team member that crossed the line. It is called sharing. Collaboration and membership as part of a team extends beyond the running to the reward component too. You would want a medal as well, or to share time holding the reward like the hoisting of the Stanley Cup and a skate around the rink by every winning team member (and a day at home in private with the Cup as well). Importantly, peer review has intrinsic merit and is a valid academic activity (Scott 2007). It is profoundly important as a form of discussion about what is acceptable, novel, and important in academia. Unfortunately, it is largely underappreciated. Parsimony would dictate that instead of involving third parties to grant recognition and further legitimize the time we spend on these sometimes lengthy 'discussions', payment in some form, perhaps money, would be a fair and immediate solution. Or, we adopt another model altogether to handle reviews and publish our work.

\section{Cursory public comment by ecologists}

As a means to externally validate one of the simplest solutions to the current review/publication model (payment)-before we throw the baby out with the bathwater-I polled the Ecolog listserve starting December $3^{\text {rd }}$, 2011 for one week only. I view this as a brief fishing expedition to examine whether I was 'out to lunch' on the topic. To do this, I presented five direct questions and provided an additional open-ended comment box. The questions addressed the following topics: roles in peer reviewing; gender; whether referees should be paid in ecology and evolutionary biology; if they did get paid, how much; and who should pay. The total number of respondents was 403 (which represents only $3 \%$ of the subscriber pool). I do not view this as a definitive test of whether or not we need to be paid for reviewing but rather as a starting point for consideration of how we, as academics, want to shape the changes associated with publishing. Virtually all respondents serve as referees in ecology (96\%). Importantly, $21.7 \%$ were also associate or subject editors. A small proportion also serves as editor-in-chief for ecological journals $(3.1 \%)$. Close to half were female (43\%). This seems like a representative pool of ecologists to examine the perceived value of peer review in our field. The majority of respondents favored payment, and to my surprise, the value requested was very modest, as most indicated that $\$ 100$ per paper was fair (Figure 1). Finally, the majority of respondents indicated that publishers should pay. Interestingly, a cross-tab analysis of the individuals serving as editors even more strongly favored payment (62\% of associate/subject editors felt payment was reasonable and $63.6 \%$ of editor-in-chiefs also voted for payment). Hence, it seems we are not out to an unpaid lunch after all. 


\section{Solutions to consider}

If you are uncomfortable with accepting financial compensation, redirect the funds.

1. In the case of non-society journals, request that the payment be directed to the society of your choice.

2. In the case of society journals, request that the funds be directed to a specific aspect of the society related to research that you feel is important.

3. Direct all potential referee payments to a research body in ecology and evolution for the study of peer review in our field by academics. Research grants are allocated to academics to study and communicate with editors, authors, referees, and publishers to improve peer review. Google and many other large companies have similar research and university outreach divisions. Why should academic publishers not do the same?

4. Direct all potential referee payments to a researchgranting agency to fund more primary ecological research.

5. Direct all potential referee payments to institutions in nations that are less able to afford research or publication costs. This has the indirect benefit of increasing the diversity of publications and contributors in our field and ultimately is also good for the journals and publishers.

6. Direct all potential referee payments to increasing the number of open-access articles. Alternatively, an individual in-kind fund could be set up for you with a journal or publisher. Every time you referee for any journal associated with that publisher, credit is awarded towards your next article that is published being granted open access free of charge (which can be up to $\$ 3000$ ).

7. Direct all funds to developing peer-review materials and training courses to improve peer review for all.

If you are comfortable with accepting financial compensation, consider the following strategies.

1. Arrange to have the funds sent directly to your institution to be administered on your behalf for reimbursement to you only for specific expenses incurred (with receipts provided) associated with your research/scholarship. Costs involving attendance and presentation at a conference, society membership fees, journal page/publication charges, book purchases, or research assistant salaries would all be appropriate. Many (or most) universities already have such professional expense reimbursement programs in place-as a benefit, independent of salaries. These can be important sources of financial support, especially for those with limited or reduced (or lost) grant funding. Furthermore, they provide instant means for your institution to track how much service you are doing.

2. Accept the money, but allocate it to yourself to finance the above research/scholarship costs, or to take your graduate students out to lunch.
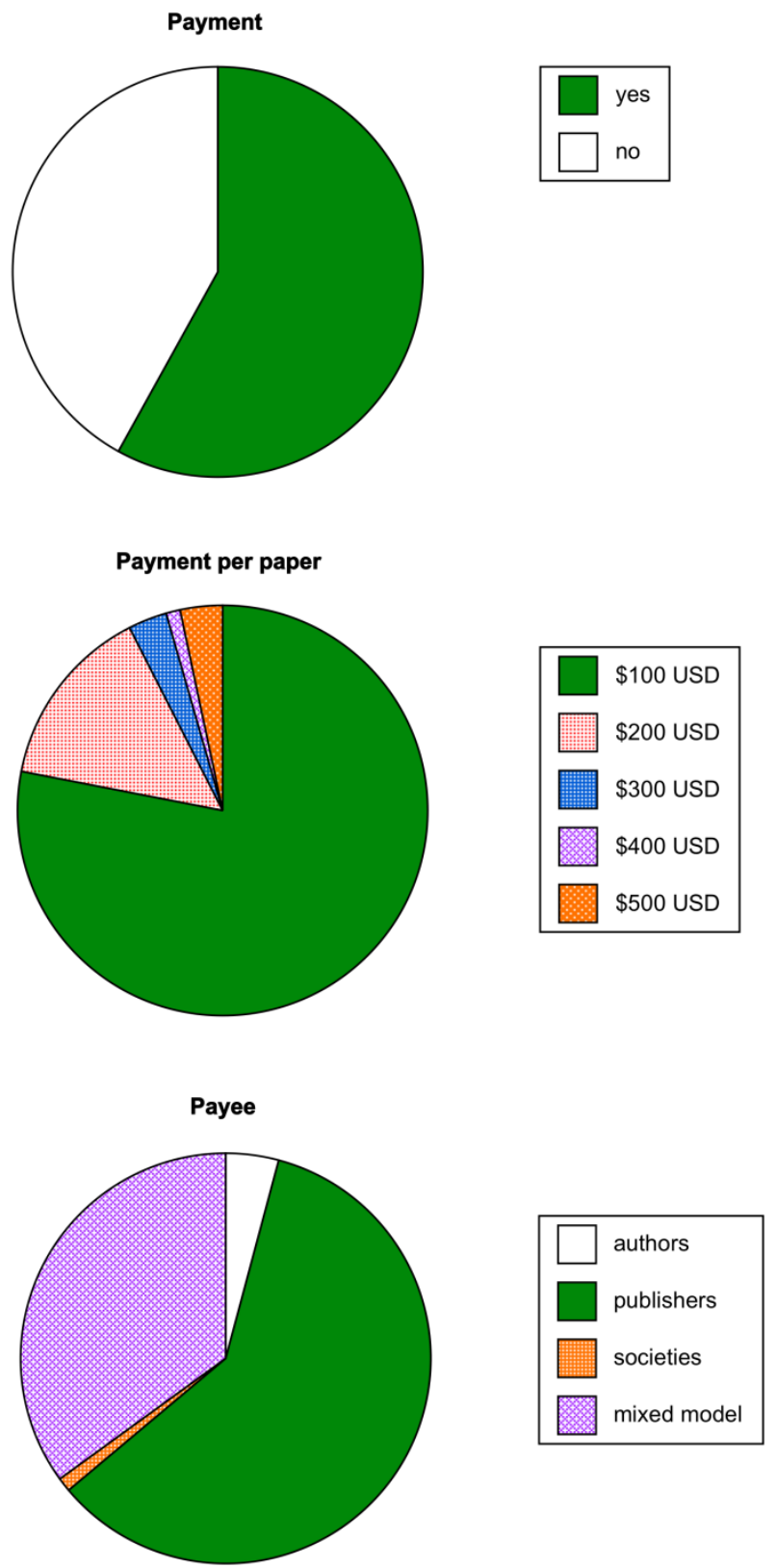

Figure 1. The findings from an online survey of ecologists ( $\mathrm{N}=403$ ) (using the Ecolog listserve) on their opinions associated with paid peer reviewing. The sizes of the pie sectors indicate relative percentages. 
In no way do I want recognition in the form of payment to undermine credibility or influence the recommendation to publish a given manuscript. It would be worthwhile to thus explore which payment model maximizes benefit, the quality of reviews, and credibility. I am pretty certain that chief editors do get paid, and I assume that we view this as acceptable because they do so much work and handle all aspects of review with the utmost professionalism. The real questions could be how referee behavior and public perception would change under a payment model. The answers to these questions - rather than merely our comfort levels - would likely shape the decision on which of the above strategies we best adopt.

\section{Implications}

The internal process of inquiry is a key element of science, and publication is a valid and useful end product of this process. It may not necessarily reflect the full scope of the dialogue that occurred, and the model is certainly not perfect. Whilst we continue to function within this system, however, it is valid to examine the allocation of benefits. Let's assume that there are profits - they need not even be significant. I do not necessarily advocate the end of the publishing industry. I do advocate that academics take control of the merit assigned post hoc to our work in all forms (citations, sales, and how they are disseminated) and demand that reviews also be granted more value (payment, publication alongside, or credit for employment or tenure). Importantly, none of us wanted the societies to pay (only $1.2 \%$ indicated this in my poll), and whilst most felt that publishers should pay, a full third of respondents indicated that a mixed model for referee payment in which the cost is shared would be appropriate. This nicely supports the culture we experience in that most individuals elect to review because we feel it is a way of paying back our peers. However, we should also ensure that the payment and benefits are shared. At some point, other commitments like family, writing, running, and teaching also intervene to prevent us from serving this role. Several important implications are thus evident. We would certainly not be expensive to the industry for our time. A payment of $\$ 100$ per paper is a nominal amount particularly because most referees report that it can take up to 7-10 hours to review a manuscript (Grod et al. 2008). So, for as little as $\$ 10$ per hour, a tipping point is reached that might cause us to put aside other tasks and take on a review. More likely is the fact that doing something unpaid often feels unappreciated whereas even a token payment validates the endeavor. In most running races now, crossing the line within a specified time gets you a medal of some sort - one for every team member in relays. Another set of implications one could envision would be individuals taking on more than they can handle, or even more radically, some individuals becoming professional, specialized referees. I do not envisage either becoming problematic. There are always editors to ensure that the quality of reviews is sufficient. If an individual takes on too many, and quality decreases, editors would not invite that person to do another review. If an individual chooses to become a professional referee, then the most likely outcome is that the quality would be high because reviewing is their livelihood and they would wish to continue receiving requests. The axiom that you get what you pay for might apply here - $\$ 0$ gets you whatever a busy referee feels like providing while even nominal payment gets you much more, or a review done at all. Far more likely drivers of reduced quality are individuals with vested interests in either promoting their own research agenda or in favoring colleagues. A recent modeling exercise demonstrates that these very 'rational' referee tendencies would unfortunately lower the net quality of our science (Thurner and Hanel 2011). Independent paid referees, even on rotational staff much like editors, might actually increase the quality of published science by eliminating these biases to some extent. We could even consider having different kinds of referee on paid staff, including those experts in statistics, design, or specific research themes. Finally, as pointed out by a survey respondent, having an opinion of getting paid for something, even shared widely, does not mean that we should get paid. Discourse is the best approach. Hence, I want to remind the reader that this exercise was undertaken as a means to encourage ecologists to consider what we do for free as valuable and to consider crossing the finish line in the peer-review model with publishers instead of letting them decide because, by necessity, their bottom line is more likely to focus on profits and not science.

Reviewing must and will continue evolving. Let's make these decisions in collaboration with publishers. Many positive and successful alternatives are already in place with respect to the academic review model, including open review, double-blind review, and posting data and papers online prior to submission to a journal for community feedback. Online peer review is also rapidly evolving in many other contexts, including the review of websites (www.hypothes.is) and ratings on both the content and the referee posted directly on most major discussion sites. We need to ensure that any changes adopted best reflect our quest as ecologists for truth in understanding the natural world. We are clearly up for discussion with the rest of the race team. Publishers? 


\section{References}

Davidoff, F. 2006. Improving peer review: who's responsible? British Medical Journal 328: 657-658. CrossRef

Fox, J. and O.L. Petchy. 2010. Pubcredits: fixing the peer review process by 'privatizing' the reviewer commons. Bulletin of the Ecological Society of America July.

Giles, J. 2006. Journals submit to scrutiny of their peerreview process. Nature 439: 252. CrossRef

Grod, O., Budden, A.E., Tregenza, T., Koricheva, J., Leimu, R., Aarssen, L.W. and C.J. Lortie. 2008. Systematic variation in reviewer practice according to country and gender in the field of ecology and evolution. PlosOne 3: e3202. CrossRef

Hauser, M. and E. Fehr. 2007. An incentive solution to the peer review problem. Plos Biology 5: e107. CrossRef
Hochberg, M.E. 2010. Youth and the tragedy of the reviewer commons. Ideas in Ecology and Evolution 3: 8-10.

Hochberg, M.E., Chase, J.M., Gotelli, N.J., Hastings, A. and S. Naeem. 2009. The tragedy of the reviewer commons. Ecology Letters 12: 2-4. CrossRef

Scott, A. 2007. Peer review and the relevance of science. Futures 39: 827-845. CrossRef

Thurner, S. and R. Hanel. 2011. Peer-review in a world with rational scientists: Toward selection of the average. The European Physical Journal B 84: 707711. CrossRef

van Kolfschooten, F. 2002. Can you believe what you read? Nature 416: 360-363. CrossRef

Ware, M. 2008. Peer Review: benefits, perceptions and alternatives. Publishing Research Consortium Summary Papers 4: 1-22. 